\title{
Multiple Propagation Effects on Genetic Estimates of Rooting for Western Hemlock
}

Cecil T. Pounders

Department of Plant and Soil Science, Alabama A\&M University, Normal, AL 35762

G. Sam Foster

U.S. Department of Agriculture Forest Service, Southern Forest Experiment Station, Alabama

A\&M University, Normal, AL 35762

Additional index words. Tsuga heterophylla, clone

\begin{abstract}
Analysis of clonal variation for two rooting traits of western hemlock [Tsuga heteterophylla (Raf.) Sarg.] clones indicated that realized genetic gain would be improved by more effective partitioning and reduction of environmental differences associated with clones. Interactions between clones and multiple propagation dates were significant, but clone rank changes between dates were minor. Number of meted cuttings per plot (RC) and number of main roots per cutting (MR) were more highly correlated genetically (1.06) than phenotypically $(0.36)$. Broad-sense heritabilities $\left(\mathrm{H}_{x}^{2}=0.62\right.$ and $\mathrm{H}_{x}^{2}=0.79$ for $\mathrm{RC}$ and $\mathrm{MR}$, respectively) and predicted genetic gain from clonal selection were moderately high. Both the percentage of rooted cuttings and root system quality could be rapidly improved by the clonal selection procedures used.
\end{abstract}

Compared with seed propagation, asexual propagation of "select" trees offers gains in growth, pest resistance, uniformity, and other desirable traits (Roulund, 1973). A vegetative propagule (ramet) is a genetic copy of the ortet (original seedling); thus, desirable traits can be transmitted to ramets to produce a clone. Vegetative propagules with superior traits can be used for genetic studies, to establish seed orchards, or be released as named cultivars.

Variation observed among ramets within a clone (intraclonal) originates from changes in physiological factors due to environmental effects. Differences in propagule response to environmental factors such as light, moisture, fertility, and temperature can determine how the genetic potential of a clone is expressed. Environmental factors acting on the ortet may be carried forward in propagules of a clone for various periods (Cannell et al., 1978; Libby and Jund, 1962). Environmental factors that persist to affect successive generations and that inflate differences among clones are generally referred to as $\mathrm{C}$ effects (Wilcox and Farmer, 1968).

Estimates of total genetic variation can be inflated if substantial environmental variation is confounded with intraclonal variation. Biased estimates of genetic variation influence estimates of genetic parameters such as heritability, correlations among traits, and expected gain from selection. Traits measured shortly after cloning are most subject to overestimation of genetic variance due to C effects (Libby and Jund, 1962). The presence and size of environmental effects may have an important bearing on the success of a tree improvement program since they might cause the erroneous selection of genetically inferior clones.

Various $\mathrm{C}$ effects that influence rooting traits of trees have been observed. As the age of the ortet increases, the rooting ability of cuttings generally decreases (Brix and van den Driessche, 1977). Tree species vary in the rate of ontogenetic decrease (Foster et al., 1981; McAlpine and Jackson, 1959; Roulund, 1973), with the loss of rooting ability being generally irreversible (Olesen, 1978). Roulund (1973) found an average increase

Received for publication 9 Sept. 1991. Accepted for publication 11 Mar. 1992. The cost of publishing this paper was defrayed in part by the payment of page charges. Under postal regulations, this paper therefore must be hereby marked advertisement solely to indicate this fact. in rooting of $2.5 \%$ per whorl as cutting origin changed from the top to the bottom of the crown in Norway spruce [Picea abies (L.) Karst.]. Plant health and vigor have been observed to have a very positive effect on rooting ability (Dormling and Kellerstam, 1981). Other factors affecting rooting ability include reproductive organs on cuttings (Burden and Shelbourne, 1974), position within a branch, and cutting size (Ying and Bagley, 1977).

In cottonwood (Populus deltoides Bartr.), $\mathrm{C}$ effects accounted for $9 \%$ to $11 \%$ of the total phenotypic variation (one-third the total genetic variation) for two rooting traits (Wilcox and Farmer, 1968). Analysis of phenotypic variation for five rooting traits of western hemlock demonstrated that the potential bias to genotypic values of clones owing to $\mathrm{C}$ effects was significant, but heritability and gain estimates were only slightly biased (Foster et al., 1984). These authors suggested that efforts be made to minimize or control variation owing to $\mathrm{C}$ effects when selecting clones for higher rooting potential.

Clonal variation in rooting western hemlock (hereafter referred to as hemlock) has been reported by several researchers. Rooting studies conducted on a juvenile population (6 to 20 years old) and a mature population (19 to 60 years old) of hemlock found that broad-sense heritabilities for proportion of rooted cuttings per ortet were 0.53 in juvenile and 0,55 in mature populations, while for number of main roots per rooted cutting, heritabilities were 0.31 in juvenile and 0.27 in mature populations (Foster et al., 1981). Product-moment correlations of the two traits with age of ortet, calculated separately for the two populations, were significant. They ranged between -0.14 to -0.21 and indicated that a small decline in rooting ability occurs as ortet age increases. When open-pollinated families of 1 -year-old hemlock seedlings were used as ortets, broad-sense heritability was estimated on an individual plant basis as 0.23 and narrow-sense heritability as 0.04 for the percentage of rooted cuttings per ortet (Sorensen and Campbell, 1980).

This study had three objectives: 1) to evaluate the importance of several environments on the estimation of genetic control of two rooting ability traits among clones; 2) to determine the

Abbreviations: MR, main root, RC, rooted cuttings. 
degree of genetic, phenotypic, and environmental relationship between the two rooting traits; and 3) to predict the level of genetic gain from selection of the best clones in the population.

\section{Materials and Methods}

Twenty hemlock ortets were randomly chosen from trees included in a low-intensity, comparison-tree selection program located in Crown Zellerbach Corp.-managed forests between Clallam Bay, Wash. $\left(48^{\circ} 15^{\prime} \mathrm{N}\right.$ latitude) and Tillamook, Ore. $\left(45^{\circ} 30^{\prime} \mathrm{N}\right.$ latitude) in the Coast Ranges between 0 and $300 \mathrm{~m}$ elevation. Ortets ranged between 28 to 62 years, estimated at breast height. The 20 ortets (clones) were assumed to be a random sample from the wild population, especially for rooting ability traits, since trees were not chosen for rooting characteristics, and analysis of 5th-year heights from progeny tests of trees in the program (Foster and Lester, 1983) indicated no significant differences in total height from random seed collections.

Stem cuttings were collected from the previous year's last growth cycle in the top one-third of the crown of parent trees in Jan. 1976 and were rooted in mist benches. The rooted cuttings of each ortet were potted in Feb. 1977. The cuttings (primary ramets) were grown in a greenhouse for two growing seasons and uniformly hedged in the late winters of 1978 and 1979 to develop stock plants (shorter than $0.5 \mathrm{~m}$ ). All ramets were grown in 11.4-liter pots with the same potting medium (1 sand : 1 peat : 1 perlite, by volume) under uniform environmental conditions in a shade house near Portland, Ore., with ambient daylength and temperature.

Stem cuttings from previous year's growth used in this study were removed from a single hedged primary ramet of each of the 20 clones and set at two dates (14 Dec. 1980 and 17 Feb. $1982) \approx 1$ year apart. Before being set, each cutting was reclipped to a standard length of $10 \mathrm{~cm}$, when possible. The majority of the cuttings met the standard length $(X=9.4 \mathrm{~cm}$ Put, range 3.5-12.0 cm). Needles were removed from the lower 2 $\mathrm{cm}$ of the cutting base. Cuttings were then quickly dipped into a solution of methyl 1-(butylcarbamoyl)-2-benzimidazolecarbamate (benomyl) (0.15 g.liter $\left.{ }^{-1}\right)$ and water, lightly tapped to remove excess solution, and dipped (lower $2 \mathrm{~cm}$ of cutting base) into a $10 \%$ aqueous solution containing "Dip 'n Grow" [(1.0\% indole-3-butyric acid (IBA) and 0.5\% 1-naphthalene-acetic acid (NAA)] (C-R Chemical Research Co., Portland, Ore.).

Treated cuttings were set in media-filled plastic containers $(65 \mathrm{ml})$ for rooting. The medium included 1 shredded peat : 1 perlite : 1 coarse sand (by volume) and was steam-sterilized before use.

The rooting chamber consisted of a wood-framed, vinyl tent measuring $16.9 \times 1.2 \times 0.8 \mathrm{~m}$ (length/width/height) and was located inside a greenhouse. High humidity [average $80 \%$ relative humidity $(\mathrm{RH})]$ was maintained within the chambers by using an intermittent misting system. Carbon dioxide, water, and air were injected into the nozzle heads to produce a dense fog. The misting system was controlled by a combination of manual and automatic controls. When operating, a timer engaged the misting system for 1.5 to $2 \mathrm{~min}$ on a 12 -min cycle. Very little misting was required when the greenhouse air was $<15 \mathrm{C}$. The humidity was monitored and the mist system was manually operated when needed until the humidity reached at least $80 \% \mathrm{RH}$. Once the greenhouse air rose above $15 \mathrm{C}$, a thermostatically controlled system took over to maintain the temperature below $21 \mathrm{C}$ and the relative humidity above $80 \%$.

Air from inside the greenhouse was pumped into the chamber to help control temperature and humidity. The temperature inside the chamber was maintained at 10 to $13 \mathrm{C}$, November-April and 15 to 20C, May-October. Daylength was maintained at 16 $\mathrm{h}$ throughout the experiment with high-pressure sodium lights.

The cuttings were treated weekly with an application of fertilizer and fungicide. The fertilizer was applied as a $20 \mathrm{~N}-20 \mathrm{P}-$ $20 \mathrm{~K}$ foliar spray at $150 \mathrm{ppm}$ with a biweekly application of 50 to $75 \mathrm{ppm}$ chelated iron. The fungicide was applied separately as a foliar spray and rotated weekly among $1800 \mathrm{ppm} \mathrm{2,6-}$ dichloro-4-nitroaniline (Botran), 181 ppm cis- $N$ - ((Trichloromethyl)thio)-4-cyclohexene-1,2-dicarboximide (Captan), and 1190 ppm tetrachloroisophthalonitrile (Daconil).

The design consisted of a randomized complete block with eight blocks, 20 clones, and two dates per clone. Each plot consisted of a row of five cuttings from a single primary ramet. In total, there were 1600 cuttings.

After $\approx 7$ months (16 July 1981 and 16 Aug. 1982), cuttings from each of the two propagation dates were lifted and evaluated. Rooting ability was determined by counting the number of rooted cuttings per five cutting plot (RC) and the number of main roots (roots beginning at the cutting base) per rooted cutting (MR). RC expresses the overall ability of a clone to form roots on its cuttings and includes zero values. MR reflects the quality of the developing root system and is measured only for rooted cuttings, thus having no zero values.

The analysis varied somewhat between the two traits. Because RC represented a plot value, it was analyzed in its original form. Plot means were calculated and analyzed for MR. Degrees of freedom in the analysis of variance (ANOVA) were adjusted for the number of missing values. The data for each trait were examined and found to be in compliance with assumptions for analysis of variance (Sokal and Rohlf, 1969).

Components of variance were calculated by equating observed mean squares to expected mean squares and solving the resulting equations. Broad-sense heritabilities were estimated for both rooting traits. Because genotypic values of clones are estimated by the average performance for both dates, broadsense heritability is calculated on a clone-mean basis (Bridgwater, 1972). Individual tree heritability is used only if individual secondary ramets are selected. The broad-sense heritability was calculated on a clone-mean basis as follows:

$$
\mathrm{H}_{\mathrm{x}}^{2}=\frac{\sigma_{\mathrm{C}}^{2}}{\sigma_{\mathrm{C}}^{2}+\frac{\sigma_{\mathrm{D}(\mathrm{C})}^{2}}{\mathrm{~d}}+\frac{\sigma^{2}}{\mathrm{db}}}
$$

Symbols are defined in Table 1.

Expected genetic gain was estimated for response of rooting traits to clonal selection. Gain $(G)$ was calculated using the following equation (Falconer, 1989):

$$
\mathrm{G}=\mathrm{iH}_{\mathbf{x}}^{2} \sigma_{\mathbf{x}}
$$

where $\mathrm{i}$ is the selection intensity $[10 \%(\mathrm{i}=1.755)$ was assumed], $\mathrm{H}_{x}^{2}$ is the broad-sense heritability, and $\sigma_{\mathbf{x}}$ is the phenotypic $\left(\omega_{\mathrm{C}}^{2}+\sigma_{\mathrm{P}(\mathrm{C})}{ }^{2} / \mathrm{d}+\sigma^{2} / \mathrm{db}\right) \boldsymbol{F}^{*} \boldsymbol{r}_{\mathrm{r}} \quad \mathrm{RC}$.

Genetic and phenotypic correlations between the two traits were also estimated using the technique of Johnson et al. (1955). To calculate correlations between RC and MR, all zero-valued plots for RC were deleted for correlation purposes. Genetic correlation was calculated as follows:

$$
\Gamma_{\mathrm{G}(\mathrm{X}, \mathrm{Y})}=\frac{\sigma_{\mathrm{C}(\mathrm{X}, \mathrm{Y})}}{\sigma_{\mathrm{C}(\mathrm{X})} \sigma_{\mathrm{C}(\mathrm{Y})}}
$$


Table 1. Analysis of variance for number of rooted cuttings per plot (RC) and main roots per rooted cutting (MR) of hemlock.

\begin{tabular}{|c|c|c|c|c|}
\hline \multirow{2}{*}{$\begin{array}{l}\text { Source } \\
\text { of variation }\end{array}$} & \multirow[b]{2}{*}{ df } & \multicolumn{2}{|c|}{ Mean squares } & \multirow[b]{2}{*}{ Expected mean squares ${ }^{z}$} \\
\hline & & $\mathrm{RC}$ & MR & \\
\hline Dates(D) & 1 & $27.66^{* * y}$ & $145.20^{* * y}$ & $\begin{array}{l}\sigma^{2}+b \sigma_{D C}^{2}+c \sigma_{B(D)}^{2}+ \\
\quad c b \sigma_{D}^{2}\end{array}$ \\
\hline Blocks(B)/D & 14 & $1.02^{\mathrm{NS}}$ & $2.28^{N S}$ & $\sigma^{2}+C \sigma_{B(D)}^{2}$ \\
\hline Clones(C) & 19 & $6.47^{*}$ & $19.88^{* *}$ & $\sigma^{2}+b \sigma_{D C}^{2}+b d \sigma_{C}^{2}$ \\
\hline $\mathrm{D} \times \mathrm{C}$ & 19 & $2.42^{* *}$ & $4.45^{* *}$ & $\sigma^{2}+b \sigma_{D C}^{2}$ \\
\hline Error & 210 & 1.22 & 1.83 & $\sigma^{2}$ \\
\hline
\end{tabular}

${ }^{z} d, b$, and $c$ are values for the number of dates(2), blocks(8), and clones(20), respectively; $\sigma_{D}{ }^{2}$, is variance among dates; $\sigma_{B(D)}{ }^{2}$, is variance among blocks within dates; $\sigma_{\mathrm{C}}{ }^{2}$, is variance among clones; $\sigma_{\mathrm{DC}}{ }^{2}$, is variance owing to interactions of dates and clones; $\sigma^{2}$ is the error variance.

'A synthetic F test, after the technique of Cochran (1951) was used to test for differences among dates.

Ns, ****Nonsignificant at $P=0.05$ or significant at $P=0.05$ or 0.01 , respectively.

where $\Gamma_{\mathrm{G}(X, Y)}$ is the genetic correlation between traits $\mathrm{X}$ and $\mathrm{Y}$, $\sigma_{\mathrm{C}(\mathrm{X}, \mathrm{Y})}$ is the clonal component of covariance between traits $\mathrm{X}$ and $Y, \sigma_{C(X)}$ is the square root of the clonal component of variance for trait $\mathrm{X}$, and $\sigma_{\mathrm{C}(\mathrm{Y})}$ is the square root of the clonal component of variance for trait Y.

The phenotypic correlation between traits was calculated as follows:

$$
\Gamma_{\mathrm{P}(\mathrm{X}, \mathrm{Y})}=\frac{\mathrm{MCP}_{\mathrm{C}(\mathrm{X}, \dot{\mathrm{Y}})}}{\left(\mathrm{MS}_{\mathrm{C}(\mathrm{X})} \mathrm{MS}_{\mathrm{C}(\mathrm{Y})}\right)^{1 / 2}}
$$

where $\Gamma_{\mathrm{P}(\mathrm{X}, \mathrm{Y})}$ is the phenotypic correlation between traits $\mathrm{X}$ and $\mathrm{Y}, \mathrm{MCP}_{\mathrm{CXXY}, \mathrm{S}}$ is the clonal mean cross product between traits $X$ and $Y, M_{C(X)}$ is the clonal mean square for trait $X$, and $\mathrm{MS}_{\mathrm{C}(\mathrm{Y})}$ is the clonal mean square for trait $\mathrm{Y}$.

Clone rank differences between dates were tested by Spearman rank correlation (Sokal and Rohlf, 1969) as follows:

$$
\Gamma_{\mathrm{s}}=1-\frac{6 \epsilon\left(\mathrm{R}_{1}-\mathrm{R}_{2}\right)^{2}}{\mathrm{n}\left(\mathrm{n}^{2}-1\right)}
$$

where $R_{1}$ is the ranking of a clone's trait mean for date $1, R_{2}$ is the same clone's trait mean rank for date 2 , and $n$ is the number of clones.

\section{Results and Discussion}

The results of this study allow the partitioning of phenotypic variation into total genetic variation and environmental effects. Estimates of genetic variation, heritabilities, and predicted genetic gain from clonal selection were influenced by environmental effects. Significant variation was indicated among the 20 clones for both rooting traits (Table 1). Clonal variation with respect to $\mathrm{RC}$ and $\mathrm{MR}$ accounted for $14 \%$ and $24 \%$ of each trait's total model variation, respectively (Table 2). Variation among blocks per date was nonsignificant for both traits (Table 1). This result indicates a high degree of uniformity existed within the propagation environment during both rooting trials. Based on overall average rooting of $59 \%$ for Dec. 1980 and $40 \%$ for Feb. 1982, propagation date constituted a significant source of total variation for both MR (22\% of total variation) and RC (9\% of total variation) (Tables 1 and 2 ).

Date $\times$ clone interactions were significant for both traits
Table 2. Estimated variance components and $\mathrm{SE}^{\mathrm{z}}$ (in parentheses) for number of rooted hemlock cuttings per five cutting plot (RC) and

\begin{tabular}{|c|c|c|c|c|}
\hline \multirow[b]{2}{*}{$\begin{array}{l}\text { Variance } \\
\text { component }\end{array}$} & \multicolumn{2}{|c|}{$\mathrm{RC}$} & \multicolumn{2}{|c|}{ MR } \\
\hline & Estimate & $\begin{array}{c}\text { Total } \\
\text { variation } \\
(\%)\end{array}$ & Estimate & $\begin{array}{c}\text { Total } \\
\text { variatior } \\
(\%)\end{array}$ \\
\hline$\sigma_{D}^{2}$ & $0.16(0.141)$ & 9 & $0.88(0.741)$ & 22 \\
\hline$\sigma_{B(D)}^{2}$ & $0.00(0.019)$ & 0 & $0.02(0.041)$ & 1 \\
\hline$\sigma_{\mathrm{C}}^{2}$ & $0.25(0.133)$ & 14 & $0.96(0.154)$ & 24 \\
\hline$\sigma_{\mathrm{DC}}^{2}$ & $0.15(0.095)$ & 8 & $0.33(0.173)$ & 8 \\
\hline$\sigma^{2}$ & $1.22(0.118)$ & 69 & $1.83(0.179)$ & 45 \\
\hline
\end{tabular}
number of main roots per rooted cutting (MR). ${ }^{r}$

${ }^{\mathrm{z}}$ Namkoong (1979).

${ }^{\mathrm{Y}}$ Calculated from observed mean squares in Table 1.

Table 3. Estimated broad-sense heritabilities and potential genetic gains based on clonal selection for number of hemlock rooted cuttings per five cutting plot (RC) and number of main roots per cutting

\begin{tabular}{lcc}
\hline \hline & RC (no.) & MR (no.) \\
\hline Mean $(\overline{\mathrm{X}})$ & 3.0 & 3.6 \\
Phenotypic sD $\left(\sigma_{\mathrm{x}}\right)$ & 1.3 & 1.8 \\
Range of clone means & $1-5$ & $1-14$ \\
CV $(\%)$ & 43 & 49 \\
Heritability & 0.62 & 0.79 \\
& \multicolumn{2}{c}{ Genetic gain $^{2}$} \\
Measured units & 0.73 & 1.10 \\
Percentage & 25 & 30 \\
\hline
\end{tabular}

${ }^{2}$ Assuming a $10 \%$ selection intensity, $\mathrm{i}=1.755$.

$\mathrm{y} \frac{\boldsymbol{\sigma}}{\mathrm{X}} \times(100)=\mathrm{cv}$.

(Table 1), indicating that average performance by clone may vary between setting date. For both $\mathrm{MR}$ and $\mathrm{RC}$, the interaction accounted for $8 \%$ of total variation (Table 2 ), which is $\approx 40 \%$ the size of clonal variation. A Spearman rank correlation calculated between the clone MR mean rankings for the two dates indicated a significant $(P<0.05)$ correlation $\left(r_{s}=0.81\right)$ in rank; hence, only minor rank changes among clones had occurred between the two dates. The Spearman rank correlation $\left(r_{s}=0.43\right)$ between the RC clone mean rankings for each date barely failed $(P=0.06)$ to meet the standard 5\% significance level. One clone, ranked lowest for the first propagation date and fifth highest for the second date, accounted for one-third of the variation in rank change for RC. With this one exception, only minor rank changes were indicated for $\mathrm{RC}$ for the two dates. Therefore, although the ANOVA indicated significant shifts in clonal rooting between setting dates, rank correlation was high enough to indicate a rather similar rooting performance for clones between setting dates.

Broad-sense heritabilities on a clone-mean basi $\left(\mathrm{H}_{\mathbf{x}}^{2}\right)$ were 0.62 for $\mathrm{RC}$ and 0.79 for $\mathrm{MR}$ (Table 3), indicating observed differences in rooting ability among clones in this experiment were due largely to genetic effects. If the variation due to propagation date had been completely confounded with genetic variation by making estimates based on a single propagation date, heritabilities would have been inflated by the clone $\times$ date interaction. This misguided result would have led geneticists to think that rooting ability was more highly inherited than it is.

Estimates for heritabilities of hemlock rooting traits on a clonemean basis by Foster et al. (1984) were 0.87 for RC and 0.92 for MR, which were in agreement with data recalculated on a 
clone-mean basis from an earlier hemlock study (Foster et al., 1981). These reported estimates are higher than estimates of this study $(\mathrm{RC}=0.62$ and $\mathrm{MR}=0.79)$. Differences between estimates of heritability in this study and the earlier estimates may be due to the previous studies having been based on only one propagation date.

In study of loblolly pine (Pinus taeda L.), Foster (1990) found significant differences in rooting percentages among three propagation dates. Additionally, he partitioned total genetic variation into additive, dominance, and epistatic effects. He found virtually all of the genetic variation was due to additive genetic control. Data from the present study indicate that one propagation date would bias estimates of heritability with an unpartitioned $\sigma_{\mathrm{DC}}{ }^{2}$ confounded with $\sigma_{\mathrm{C}}{ }^{2}$ in the numerator value used to calculate heritabilities. Estimates based on one date are biased upward $\left(\sigma_{\mathrm{C}}^{2}+\sigma_{\mathrm{DC}}{ }^{2}\right)$ by $30 \%$ for RC and $16 \%$ for MR.

Predicted genetic gains by selecting the top $10 \%$ of the clones (two of 20) expressed as a percentage improvement over the population mean were $25 \%$ for RC and $30 \%$ for MR (Table 3 ). This level of selection intensity was chosen to be representative of a reasonable level for a normal-sized program that could contain several hundred clones. Variation among clones for both rooting traits was large, contributing to the substantial genetic gain predicted for each trait. Considerable differences in clone means occurred; the phenotypic cv was $\approx 45 \%$ for both traits (Table 3). The large genetic gains (Table 3) seem reasonable because genetic gain depends heavily on both heritability and variation among clone means. This relationship suggests that one generation of clonal selection for rooting traits could produce substantial changes in population means.

Our results indicated that RC and MR are closely associated genetically and phenotypically. The genetic correlation was 1.06 (representing perfect correlation; that is, the same genes condition both traits), the phenotypic correlation was 0.36 and the environmental correlation was 0.17 . Since the genetic correlation is high and positive, selection for either rooting trait based on clone-mean performance would result in a shift of the other character in the same direction. Direct selection for MR has a higher heritability and would produce a higher correlated response in RC, whereas RC can be evaluated faster and still produce good response for both traits. After one generation of selection among hemlock clones, improvement in the proportion of rooted cuttings and quality of the root system is predicted to be substantial.

\section{Implications}

This study employed four techniques that have been proposed (Foster et al., 1984) to increase precision in selecting genetically superior clones for rooting characters. The first technique involved the collection of cuttings from the same crown position in each ortet selected for cloning. This reduced the $\mathrm{C}$ effects associated with rooting ability that have been demonstrated to occur as cutting position changes within the crown of an ortet (Foster et al., 1984; Roulund, 1973).

The second technique involved secondary cloning, the process of rooting the cuttings (primary ramets) from the ortet, then taking cuttings (secondary ramets) from the rooted primary ramets. Uniform treatment of the primary ramets increased the vigor and uniformity of cuttings used in this study to produce secondary ramets of each clone. Secondary cloning served to reduce physiological differences associated with the original ortet (i.e., nutrient levels) that could bias a clone's ability to root (Preston et al., 1953).
The third technique involved the randomization of cuttings within the rooting chamber at multiple dates. Heritability and phenotypic SD are affected by blocking and propagation under multiple environments (dates) that indirectly influence expected genetic gain. Conducting the rooting trials on multiple dates allowed a better assessment of the clonal rooting performance as compared with a single date. The goal of our program is to select clones that root well repeatedly. In an analytical sense, the genetic variance (estimated by $\sigma_{\mathrm{C}}^{2}$ ) is no longer confounded with the genotype $x$ environment interaction (estimated by $\sigma_{\mathrm{DC}}{ }^{2}$ ) when the rooting ability of the clones is assessed in two or more trials. Furthermore, the multiple trial (date) experiment provides a more realistic estimate of the phenotypic SD deviation (since $\sigma_{\mathbf{B}}^{2}$ is removed) and of the heritability estimate (since $\sigma_{c}^{2}$ and $\sigma_{\mathrm{DC}}{ }^{2}$ are not confounded).

The fourth technique was to select clones for rooting traits with high heritability. MR and RC have previously been demonstrated to have high heritability for hemlock clones selected from the wild population (Foster et al., 1984). Genetically superior individuals are easier to identify if heritabilities are high, because the phenotype more closely reflects the genotype and selection is more efficient.

Using these horticultural techniques to increase precision in clonal selection increases propagation cost. Secondary cloning, for example, requires material to be maintained for several years and lengthens the evaluation process. This would limit the number of clones that could be evaluated with given resources and reduces predicted gain per unit time. The projected increase in realized gain by removing environmental factors confounded in genetic estimates of rooting ability may offset these costs because superior clones can be identified more precisely.

Potentially, the percentage of rooted cuttings and root system quality could be rapidly improved through clonal selection in hemlock. Increased rooting ability would have a large economic impact on production cost by reducing the size of cutting orchards, rooting facilities, labor requirements, and aftercare facilities for a given production volume. Improved root system quality may also speed outplanting to the field and enhance subsequent field growth.

\section{Literature Cited}

Bridgwater, F.E., Jr. 1972. Multiple trait selection in a population of eastern cottonwood. PhD Diss., Oklahoma State Univ., Stillwater.

Brix, H. and R. van den Driessche. 1977. Use of rooted cuttings in reforestation-A review of opportunities, problems and activities. B.C. For. Ser./Can. For. Serv. Joint Rpt. no. 6.

Burden, R.D. and C.J.A. Shelbourne. 1974. The use of vegetative propagules for obtaining genetic information. N.Z, J. For. Sci. 4:418425.

Cannell, M.G.R., F.E. Bridgwater, and M.S. Greenwood. 1978. Seedling growth rates, water stress responses and root-shoot relationships related to eight-year volumes among families of Pinus taeda L. Silvae Genet. 27:237-248.

Cochran, W.G. 1951. Testing a linear relation among variances. Biometrics 7:17-32.

Dormling, I. and H. Kellerstam. 1981. Rooting and rejuvenation in propagating old Norway spruce by cuttings. Symp. on Clonal For., Swedish Univ. Agr. Sci., Dept. For. Genet. Res. Note 32. p. 6572 .

Falconer, D.S. 1989. Introduction to quantitative genetics. Wiley, New York.

Foster, G.S. 1990. Genetic control of rooting ability of stem cuttings from loblolly pine. Can. J. For. Res. 20:1361-1368.

Foster, G.S. and D.T. Lester. 1983. Fifth-year height variation in 
western hemlock open-pollinated families growing on four test sites. Can. J. For. Res. 13:251-256.

Foster, G.S., J.A. Martin, and T.D. Caldwell. 1981. Genetic variation in the rooting of western hemlock cuttings. Crown Zellerbach Corp., Res. Manuscript no. 32.

Foster, G.S., R.K. Campbell, and W.T. Adams. 1984. Heritability, gain, and $\mathrm{C}$ effects in rooting of western hemlock cuttings. Can. J. For. Res. 14:628-638.

Johnson, H.W., H.F. Robinson, and R.E. Comstock. 1955. Genotypic and phenotypic correlations in soybeans and their implications in selection. Agron. J. 47:477-483.

Libby, W.J. and E. Jund. 1962. Variance associated with cloning. Heredity 17:533-540.

McAlpine, R.G. and L.W. Jackson. 1959. Effect of age on rooting of loblolly pine air-layers. J. For. 57:565-566.

Namkoong, G. 1979. Introduction to quantitative genetics in forestry. U.S. Dept. Agr. Tech. Bul. no. 1588.
Olesen, P.O. 1978. On cyclophysis and topophysis. Silvae Genet. 27:173-178.

Preston, W.H., J.B. Shanks, and P.W. Cornell. 1953. Influence of mineral nutrition of the parent plant and treatment of phyto hormones. Bul. 249, Dept. Agr., Union of S. Africa.

Roulund, H. 1973. The effect of cyclophysis and topophysis on the rooting ability of Norway spruce cuttings. For. Tree Improv. 5:21-41.

Sokal, R.R. and F.J. Rohlf. 1969. Biometry. W.H. Freeman, San Francisco.

Sorensen, F.C. and R.K. Campbell. 1980. Genetic variation in rootability of cuttings from one-year-old western hemlock seedlings. U.S. Dept. Agr. For. Serv. Res. Note PNW-352.

Wilcox, J.R. and R.E. Farmer, Jr. 1968. Heritability and C effects in early root growth of eastern cottonwood cuttings. Heredity 23:239245.

Ying, C.C. and W.T. Bagley. 1974. Genetic variation of eastern cottonwood. Univ. of Nebraska, Dept. For. Prog. Rpt. 1. 